\title{
PENGARUH GAYA HIDUP DAN TREND FASHION TERHADAP KEPUTUSAN PEMBELIAN ONLINE PRODUK FASHION PADA MEDIA SOSIAL INSTAGRAM
}

\author{
Nurul Arsita ${ }^{(1)}$ Vicky F Sanjaya ${ }^{(2)}$ \\ Universitas Islam Negeri Raden Intan Lampung \\ nurularsita08@gmail.com,vicky@radenintan.ac.id
}

\begin{abstract}
Abstrak.Penelitian ini bertujuan untuk menguji pengaruh gaya hidup dan trend fashion terhadap keputusan pembelian online pada media sosial Instagram. Metode yang digunakan dalam penelitian ini dengan kuisioner. Sampel dari penelitian ini berjumlah 41 responden. Uji statistic dilakukan dengan menggunakan Structurel Equation Modelling berbasis PLS. Uji validitas menggunakan nilai faktor loading, sedangkan uji reliabilitas menggunakan nilai Cronbach's Alpha, reliabilitas komposit dan Average Variance Extracted (AVE). Ada 3 variabel dalam penelitian ini yaitu : 2 (dua) variabel bebas $\left(\mathrm{X}_{1}\right.$ dan $\left.\mathrm{X}_{2}\right)$ dan 1 (satu) variabel terikat, dimana gaya hidup $\left(\mathrm{X}_{1}\right)$ dan trend fashion $\left(\mathrm{X}_{2}\right)$ sebagai variabel bebas dan keputusan pembelian (Y) sebagai variabel terikat. Berdasarkan hasil pengolahan data telah ditemukan jawaban hipotesis dengan kesimpulan sebagai berikut; gaya hidup berpengaruh positif signifikan terhadap keputusan pembelian dan trend fashion berpengaruh positif signfikan terhadap keputusan pembelian.
\end{abstract}

Kata kunci: gaya hidup, trend fashion, keputusan pembelian

\section{The Influence of Lifestyle and Fashion Trends on Online Purchase Decisions for Fashion Products on Instagram Social Media}

\author{
Nurul Arsita ${ }^{(1)}$ Vicky F Sanjaya ${ }^{(2)}$ \\ Universitas Islam Negeri Raden Intan Lampung \\ nurularsita08@gmail.com,vicky@radenintan.ac.id
}

\begin{abstract}
This study aims to examine the effect of lifestyle and fashion trends on online purchasing decisions on Instagram social media. The method used in this research is a questionnaire. The sample of this study amounted to 41 respondents. The statistical test was carried out using PLS-based Structurel Equation Modeling. The validity test uses the loading factor value, while the reliability test uses the Cronbach's Alpha value, composite reliability and Average Variance Extracted (AVE). There are 3 variables in this study, namely: 2 (two) independent variables (X1 and X2) and 1 (one) dependent variable, where lifestyle (X1) and fashion trends (X2) are independent variables and purchasing decisions (Y) are variables. bound. Based on the results of data processing has been found answers to the hypothesis with the following conclusions; lifestyle has a significant positive effect on purchasing decisions and fashion trends have a significant positive effect on purchasing decisions.
\end{abstract}

Keywords: lifestyle, fashion trends, purchasing decisions 


\section{PENDAHULUAN}

Kehadiran teknologi dan informasi yang kian pesat memungkinkan seseorang untuk mengetahui perkembangan secara global. Media sosial telah menjadi bagian yang tidak dapat dipisahkan oleh aktifitas kehidupan sehari-hari hampir semua orang. Perkembangan arus globalisasi di zaman sekarang mengakibatkan kemajuan teknologi berkembang sangat pesat dan melahirkan media sosial di kalangan masyarakat yang mendorong seseorang untuk cenderung ingin memperlihatkan dirinya dengan cara menjadi "center of attention" atau pusat perhatian (Mufidah \& Wulansari, 2018).

Salah satu media sosial yang sering diakses di Indonesia adalah Instagram. Instagram secara tidak langsung sudah bertransformasi menjadi trend gaya hidup di masyarakat. Selain itu Instagram juga kini menjadi salah satu tempat di mana trend fashion bermunculan. Penggunaan instagram tentunya dapat mempengaruhi sikap dan perilaku seseorang. Ada yang berubah menjadi seseorang yang lebih kreatif, tampil menarik, ada juga yang selalu memamerkan barang-barang yang ia punya, seolah-olah instagram sudah menjadi tempat untuk berkompetisi. Gaya hidup khususnya pada remaja saat ini lebih ingin mendapatkan pengakuan dari dunia maya dibandingkan di dunia nyata. Banyak dari mereka memposting foto atau video hanya untuk mendapatkan like dan komentar dari orang lain di media sosial.

Gaya hidup mencakup sesuatu yang lebih dari sekedar kelas sosial ataupun kepribadian seseorang. Tidak bisa dipungkiri bahwa gaya hidup saat ini banyak dipengaruhi oleh media sosial seperti Instagram. Selain itu Instagram telah menjadi pemicu dan daya tarik untuk seseorang melihat perkembangan agar tidak ketinggalan jaman. Sudah menjadi kebiasaan masyarakat di Indonesia yang selalu mengikuti suatu kecenderungan. Jika konsumen bisa masuk dalam kecenderungan umum maka berarti ia termasuk golongan yang selalu mengikuti mode atau tren.

Produk Fashion sangat banyak macamnya mulai dari pakaian, sepatu dan tas yang mana produk tersebut termasuk kebutuhan setiap orang. Namun ada beberapa orang yang membeli produk hanya karena memenuhi keinginan bahkan meniru teman, saudara atau artis idola. Dalam menggambarkan tren fashion dapat dilihat dari bagaimana mengekspresikan diri dari apa yang mereka lihat dan minati. Pada era saat ini instagram banyak menampilkan foto dan video yang menjadi inspirasi outfit kekinian. Beberapa orang merasa kecewa telah mengikuti trend karena outfit yang mereka kenakan memiliki kesamaan dengan beberapa orang yang mereka jumpai. Beberapa dari mereka menghabiskan uang dengan terus-menerus membeli produkproduk yang sesuai dengan trend tetapi tidak menyesuaikan dengan diri sendiri. Bahkan terkadang mereka lupa dengan koleksi pribadinya. Hal ini dibuktikan ketika hendak berpergian seseorang akan menghabiskan separuh waktu untuk mencari sesuatu yang akan dikenakan.

\section{TINJAUAN TEORITIS}

\section{Gaya Hidup}

Menurut Sutisna dalam Heru Suprihhadi (2017) gaya hidup secara luas didefinisikan sebagai cara hidup yang diidentifikasi oleh bagaimana orang lain menghabiskan waktu mereka (aktivitas) dilihat dari pekerjaan, hobi, belanja, olahraga, dan kegiatan sosial serta interest 
(minat) terdiri dari makanan, mode, keluarga, rekreasi dan juga opinion (pendapat) terdiri dari mengenai diri mereka sendiri, masalah-masalah sosial, bisnis, dan produk. Gaya hidup mencakup sesuatu yang lebih dari sekedar kelas sosial ataupun kepribadian seseorang. Gaya hidup adalah sekumpulan perilaku yang mempunyai arti bagi individu maupun orang lain pada suatu saat di suatu tempat, termasuk di dalam hubungan sosial, konsumsi barang, entertainment, dan cara berbusana. (Alfred Adler dalam Priansa, 2017:185)

Konsumen lebih mengutamakan kualitas produk daripada gaya hidup karena akan menjadi nilai tersendiri bagi mereka untuk melakukan keputusan pembelian (Hadaita Rahmah, 2019). Akan tetapi menurut Aulia Rahma (2019) dan Naufal Apritama Rahmadika, dkk (2019) perkembangan gaya hidup menyesuaikan keputusan pembelian sehingga daya beli konsumen semakin meningkat. Gaya hidup erat kaitannya dengan pilihan produk seseorang agar sesuai dengan gaya hidup yang dipilih (Moch. Farizy Hardiansyah Kuncoro, 2020). Dan konsumen akan lebih memilih melakukan pembelian atas dasar pengaruh gaya hidup yang dinilai cukup membantu konsumen yang mengutamakan keinginan mereka (Eni Nur Aini, 2020).

Gaya Hidup (Life Style) merupkan penerapan pola kehidupan yang dipengaruhi oleh hobi, pekerjaan, keinginan, dan faktor sosial seperti media sosial. Hanya dengan melihat dan mengamati akan menimbulkan rasa keinginan yang tinggi dan juga rasa gengsi yang tentunya membuat konsumen tak perlu berpikir panjang akan keputusannya. Hal ini akan meningkatkan suatu keputusan pembelian seorang konsumen pada suatu produk.

\section{Trend Fashion}

Salah satu hal yang menyebabkan fashion menjadi sangat popular adalah karena pakaian yang modis, aksesoris, dan bendabenda mode lainnya sangat mudah terlihat walaupun hanya sekilas. Sebuah tas bermerek, sepatu mahal, perhiasan mewah, dan tata rambut model terbaru bisa dengan cepat menunjukan status sosial seseorang. Maka mode terus berubah dari waktu ke waktu dan tentu saja membutuhkan biaya yang sangat besar. Mode merupakan cara untuk menunjukan eksistensi. Mereka pun berlomba untuk selalu mengikuti tren atau bahkan berusaha menjadi trendsetter. Padahal tren memang dirancang untuk selalu berubah dan ini memicu pola hidup konsumtif (Peti Pera, 2021).

Menurut pendapat Fajar Ariyanto (2020) trend dapat berubah dengan cepat, seiring berjalannya waktu. Fashion atau gaya berbusana punya identitas dan ciri khasnya sendiri-sendiri. Secara umum model berbusana era 80 -an atau era 90 -an sangat berbeda dengan generasi sekarang yang akrab disebut era kekinian atau milenial. Fashion telah menjadi bagian penting dari gaya, tren, dan penampilan kehidupan sehari-hari, jadi fashion trend adalah sesuatu yang berkembang dalam suatu masyarakat sebagian besar di istilah gaya busana. Ada banyak alasan untuk konsumen untuk mengikuti tren seperti mencegah diri dari ketinggalan zaman, untuk aktualisasi diri, memenuhi kebutuhan batin, untuk meningkatkan kepercayaan diri dan mendapatkan pengakuan dari orang lain. Hal ini tentu berdampak pada perilaku belanja masyarakat yang dapat menciptakan budaya baru dalam masyarakat. (Intisari Haryanti, 2020)

Cara orang berpakaian sangat berhubungan dengan bagaimana ia 
menghargai dirinya sendiri dan orang lain. Pakaian juga menjadi sebuah symbol status social, bagaimana seseorang dalam sebuah kelas social menghabiskan waktu dan uangnya. Thorstein Veblen seorang pakar ekonomi dari Amerika Serikat dalam bukunya "The Theory Of The Leisure Class" yang dikutip oleh Baruna Tyaswara, dkk (2017) menyebutkan bahwa berpakaian adalah cara paling mudah untuk mengekspresikan kekayaan bahkan dengan menunjukkan bahwa mereka membayar orang lain hanya untuk merawat baju-baju mereka. Perilaku fashion ini menjadi sebuah lambing kekayaan yang paling menonjol.

Trend Fashion adalah bentuk pengaplikasian dari busana atau asesories yang dipakai sesuai dengan perkembangan zaman. Trend fashion selalu dapat berubah seiring berjalannya waktu dan selalu memunculkan model terbaru yang inovatif. Adanya internet dan media online layaknya instagram yang menampilkan banyak inspirasi terkait fashion yang kekinian memungkinkan para penggunanya untuk mengikuti trend. Hal tersebut tentu memunginkan seorang konsumen memiliki keputusan pembelian agar selalu terlihat fashionable.

\section{METODE PENELITIAN}

Penelitian ini merupakan penelitian survey dengan perolehan data yang menggunakan instrumen kuisioner. Level penelitian ini adalah individu dengan usia berkisar antara 18-30 tahun. Responden merupakan individu yang aktif menggunakan media sosial instagram untuk melakukan pembelian produk fashion.
Uji statistic dilakukan dengan menggunakan Structurel Equation Modelling berbasis PLS. Uji validitas menggunakan nilai factor loading dengan melihat nilai minimum yaitu $\geq 0.6$ (Hair et al. dalam Melia Purwita Sari, 2020) dari masing-masing indikator pada item kuesiuoner, sedangkan uji reliabilitas menggunakan Cronbach's Alpha dengan minimal nilai 0.6 (Cooper sand Schindler, 2014). Selanjutnya melihat reliabilitas komposit dan Average Variance Extracted (AVE) $>1$. Uji Hipotesis menggunakan bantuan alat statistik smartPLS versi 3.3.2 dengan nilai signifikan $<0.05$. Jumlah sampel yang diujikan dalam penelitian yaitu sebanyak 41 responden.

\section{HASIL DAN PEMBAHASAN}

Berdasarkan hasil uji yang dilakukan mendapatkan hasil diantaranya, beberapa indikator kuesioner gugur karena memenuhi batas standar factor loading. Dari 7 indikator pada variabel Gaya Hidup (GH) tersisa 4 indikator. Pada variabel Trend Fashion (TF) dari 9 indikator tersisa 5 indikator. Kemudian untuk variabel Keputusan Pembelian (KP) dari 12 indikator tersisa 5 indikator.

Kemudian dilakukan uji validitas sehingga hasil yang diperoleh dari semua indikator tersisa berada di atas standar nilai faktor loading $>0.6$ sehingga berdasarkan Hair et al., (2010) dianggap semua indikator tersebut valid. Selanjutnya uji reliabilitas memiliki nilai cronbach's alpha, composite reliability dan Average Variance Extracted (AVE) $>0.6$ sehingga variabel tersebut dianggap reliabel dan memenuhi syarat untuk dilakukan uji hipotesis. 


\section{Hasil Uji Validitas Dan Reliabilitas}

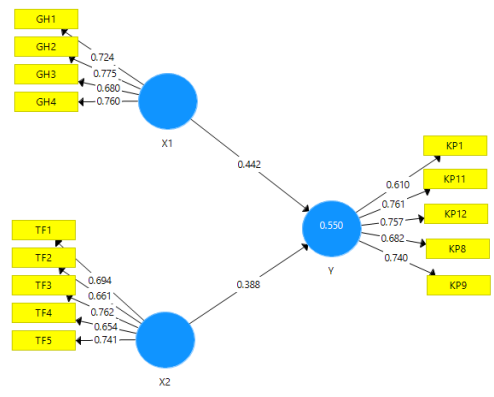

\section{Keterangan :}

GH : Gaya Hidup

TF : Trend Fashion

KP : Keputusan Pembelian

\section{Hasil Uji Validitas}

\begin{tabular}{cccc}
\hline ITEM & GH & TF & KP \\
\hline GH1 & 0.724 & & \\
GH2 & 0.775 & & \\
GH3 & 0.680 & & \\
GH4 & 0.760 & & \\
TF1 & & 0.694 & \\
TF2 & & 0.661 & \\
TF3 & & 0.762 & \\
TF4 & & 0.654 & \\
TF5 & & 0.741 & \\
KP1 & & & 0.610 \\
KP8 & & & 0.682 \\
KP9 & & & 0.740 \\
KP11 & & & 0.761 \\
KP12 & & & 0.757 \\
\hline
\end{tabular}

Sumber data diolah

\section{Hasil Uji Reliabilitas}

$\begin{array}{ccc}\text { Item } & \text { Cronbach’ } & \text { Composite } \\ \text { s Alpha } & \text { Reliability }\end{array}$

\section{Average Variance Extracted}

(AVE)

\begin{tabular}{cccc} 
GH & 0.723 & 0.825 & 0.541 \\
TF & 0.748 & 0.830 & 0.496 \\
KP & 0.758 & 0.837 & 0.507 \\
\hline
\end{tabular}

Sumber data diolah

\section{Hasil Uji Hipotesis}

\section{Hipotesis 1}

Gaya hidup berpengaruh positif dan siginifikan terhadap keputusan pembelian. Berdasarkan hasil uji yang telah dilakukan mendapatkan hasil bahwa gaya hidup berpengaruh positif dilihat dari original sampel yaitu 0.442 dan berpengaruh signifikan dengan melihat nilai $\mathrm{P}$ Value $(0.000<0.05)$. Maka dari itu hipotesis 1 di dukung. Moch. Farizy Hardiansyah Kuncoro (2020) berpendapat gaya hidup erat kaitannya dengan pilihan produk seseorang agar sesuai dengan gaya hidup yang dipilih. Semakin meningkatnya gaya hidup maka akan semakin tinggi keputusan pembelian produk.

\section{Hipotesis 2}

Trend fashion berpengaruh positif dan signifikan terhadap keputusan pembelian. Berdasarkan hasil pengujian yang dilakukan mendapatkan hasil bahwa trend fashion berpengaruh positif. Terlihat dari original sampel yaitu 0.388 dan juga berpengaruh signifikan, dilihat dari nilai $\mathrm{P}$ Value sebesar $(0.002<0.05)$. Artinya hipotesis 2 dalam penelitian ini di dukung. Dian Novita Sari, dkk (2018) menyatakan trend fashion saat ini menjadi faktor penting dalam berbisnis di dunia fashion spesifiknya memengaruhi keputusan pembelian yang dilakukan konsumen.

\section{Kesimpulan}

Berdasarkan hasil pengujian yang telah dilakukan dapat disimpulkan bahwa 
gaya hidup dan trend fashion berpengaruh positif dan signifikan terhadap keputusan pembelian konsumen secara online di media sosial instagram. gaya hidup dan trend fashion membantu proses keputusan pembelian konsumen dalam melakukan belanja online, karena konsumen akan memilih pembelian secara online sesuai dengan kegemaran menggunakan internet, frekuensi dalam berbelanja online, tingkat penggunaan media sosial dan produk yang bervariasi. Artinya kesesuaian gaya hidup dan adanya trend fashion memberikan pengaruh terhadap keputusan dalam pembelian yang dilakukan oleh konsumen.

\section{Saran}

- Penelitian selanjutnya di sarankan untuk menambahkan jumlah sampel yang diteliti agar dapat mewakili populasi dalam penelitian ini dan hasil yang diperoleh lebih akurat.

- Peneliti selanjutnya disarankan dapat untuk menambah variabel-variabel lainnya yang terkait dengan keputusan pembelian konsumen dengan beberapa faktor lain diantaranya promosi online dan orientasi belanja.

\section{DAFTAR PUSTAKA}

Aini, E. N. (2020). Pengaruh Gaya Hidup Konsumtif Dan Kualitas Produk Terhadap Keputusan Pembelian. Jurnal Bisnis dan Manajemen Islam, 8 (1), 17-27.

Ariyanto, Fajar. (2020). Pengaruh Trend Fashion Dan Pengetahuan Budaya Terhadap Keputusan Pembelian Batik Di Kampung Batik Semarang. Diakses dari https://eprints.walisongo.ac.id/id/epr
int/13288/1/Skripsi 1505026164_F ajar_Ariyanto.pdf

Haryanti, Intisari. dkk. (2020). Hedonic Motives and Fashion Trends in Decisions to Purchase Veil Clothes. Altantis Perss, vol. 465.

Kuncoro, M. F. H. (2020). Pengaruh Gaya Hidup, Citra Merek Dan Kualitas Produk Terhadap Keputusan Pembelian Produk Sandal Fipper. Diakses dari https://repository.stiesia.ac.id/id/epri $\underline{\text { nt/3139/2/PENDAHULUAN.pdf }}$

Luthfianto, D. (2017). Pengaruh Kualitas Layanan dan Gaya Hidup Terhadap Keputusan Pembelian Cafe Jalan Korea. Jurnal Ekonomi Bisnis, 22 (1), 14-25.

Mufidah, E. F., \& Wulansari, P. S. D. (2018). Gaya Hidup Hedonisme Mahasiswa Pascasarjana di Media Sosial. Jurnal Konseling Indonesia), 3(2), 33-36.

Pera, Peti .(2021). Dampak Tren Fashion Terhadap Konsep Diri Remaja Desa Penandingan Kecamatan Tanjung Sakti Pumi Kabupaten Lahat. Diakses dari http://repository.iainbengkulu.ac.id/ 6664/

Priansa \& Jonni Juni. (2017). Perilaku Konsumen Dalam Persaingan Bisnis Kontenporer. Bandung: Alfabet.

Rahma, Aulia \& Yulianti A. L. (2019). Pengaruh Store Atmospere Dan Gaya Hidup Terhadap Keputusan Pembelian Konsumen Di Matahari Departement Store. Vol 6, No 3 
Rahmadika, N. A. dkk. (2018). Pengaruh Brand Image Dan Gaya Hidup Terhadap Keputusan Pembelian Jeans Levis's (Studi Pada Mahasiswa aktif DIV Manajemen Pemasaran Jurusan Administrasi Niaga Politeknik Negeri Malang Tahun Akademik 2017/2018. Jurnal Aplikasi Bisnis, 4 (2).

Rahmah, Hadaita. (2019). Pengaruh Gaya Hidup, Harga, dan Kualitas Produk Terhadap Keputusan Pembelian Produk Sophie Martin (Studi Pada Mahasiswa Di Kota Surabaya). Diakses dari http://digilib.uinsby.ac.id/34496/2/H adaita\%20Rahmah_G73215035.pdf

Sari, Dian Novita dkk. (2018) Pengaruh Trend Fashion Terhadap Keputusan Pembelian (Survei pada Konsumen Wanita Butik Ria Miranda Cabang Malang) Jurnal Fakultas Ilmu Administrasi Universitas Brawijaya Malang.

Sari, Purwati Melia. dkk. (2020). Pengaruh Harga, Promosi dan Kepercayaan Terhadap Keputusan Pembelian Produk Y.O.U. Jurnal Enterpreneur dan Bisnis (JEBI), 1(2), 122-129.

Tyawara, Baruna. dkk. (2017). Pemaknaan Terhadap Fashion Style Remaja Di Bandung. Jurnal Komunikasi, 8 (3) 293-297. 